\title{
BREVE DESCRIÇÃO DA EPÊNTESE CONSONANTAL EM PALAVRAS DERIVADAS POR SUFIXAÇÃO NO PORTUGUÊS BRASILEIRO
}

\author{
Samanta Sá Canfield
}

Submetido em 01 de junho de 2018.

Aceito para publicação em 06 de novembro de 2018.

Cadernos do IL, Porto Alegre, n. ${ }^{\circ}$ 56, novembro. p. 57-69.

\section{POLÍTICA DE DIREITO AUTORAL}

Autores que publicam nesta revista concordam com os seguintes termos:

(a) Os autores mantêm os direitos autorais e concedem à revista o direito de primeira publicação, com o trabalho simultaneamente licenciado sob a Creative Commons Attribution License, permitindo o compartilhamento do trabalho com reconhecimento da autoria do trabalho e publicação inicial nesta revista.

(b) Os autores têm autorização para assumir contratos adicionais separadamente, para distribuição não exclusiva da versão do trabalho publicada nesta revista (ex.: publicar em repositório institucional ou como capítulo de livro), com reconhecimento de autoria e publicação inicial nesta revista.

(c) Os autores têm permissão e são estimulados a publicar e distribuir seu trabalho online (ex.: em repositórios institucionais ou na sua página pessoal) a qualquer ponto antes ou durante o processo editorial, já que isso pode gerar alterações produtivas, bem como aumentar o impacto e a citação do trabalho publicado.

(d) Os autores estão conscientes de que a revista não se responsabiliza pela solicitação ou pelo pagamento de direitos autorais referentes às imagens incorporadas ao artigo. A obtenção de autorização para a publicação de imagens, de autoria do próprio autor do artigo ou de terceiros, é de responsabilidade do autor. Por esta razão, para todos os artigos que contenham imagens, o autor deve ter uma autorização do uso da imagem, sem qualquer ônus financeiro para os Cadernos do IL.

\section{POLÍTICA DE ACESSO LIVRE}

Esta revista oferece acesso livre imediato ao seu conteúdo, seguindo o princípio de que disponibilizar gratuitamente o conhecimento científico ao público proporciona sua democratização.

http://seer.ufrgs.br/cadernosdoil/index

Quinta-feira, 22 de novembro de 2018. 


\title{
BREVE DESCRIÇÃO DA EPÊNTESE CONSONANTAL EM PALAVRAS DERIVADAS POR SUFIXAÇÃO NO PORTUGUESS BRASILEIRO \\ BRIEF DESCRIPTION ABOUT CONSONANTAL EPENTHESIS IN WORDS DERIVED BY SUFFIXATION IN BRAZILIAN PORTUGUESE
}

\author{
Samanta Sá Canfield*
}

\begin{abstract}
RESUMO: A epêntese caracteriza-se pela inserção de segmento em palavras cuja principal motivação é solucionar um problema estrutural, em geral, de caráter silábico. A epêntese consonantal, especificamente, consiste no acréscimo de uma consoante na juntura morfemática de palavras derivadas. No português brasileiro, é um fenômeno consagrado na língua escrita, mas ainda pouco estudado. Neste artigo, são retomados alguns dos estudos sobre epêntese consonantal em palavras derivadas por sufixo no português brasileiro; além disso, são apresentadas ideias de diferentes autores sobre o status da consoante epentética.
\end{abstract}

PALAVRAS-CHAVE: epêntese consonantal; derivação sufixal.

ABSTRACT: Epenthesis refers to the insertion of a segment within a word which the main purpose is the solution of a structural syllabic problem. The Consonantal Epenthesis consists in adding a consonant during the word derivation process specifically. The consonantal Epenthesis is a known phenomenon in writing Brazilian Portuguese but yet it is not studied as wished. Some studies about Brazilian Portuguese consonantal Epenthesis in suffix-formed words are reviewed in this article. Furthermore, different authors' ideas about the epenthetic consonant are presented.

KEYWORDS: consonantal epenthesis; suffix-formed words.

\section{Introdução}

Em estudo anterior ${ }^{1}$, foi observado que, eventualmente, palavras derivadas com o acréscimo de sufixos sofriam epêntese de consoante, a qual era condicionada pela tonicidade da palavra. Entre os sufixos relacionados nas gramáticas, foram escolhidos -ada, -al e -eiro, por terem sido os sufixos que mais apresentavam a ocorrência do fenômeno entre os exemplos listados por gramáticas, observado em palavras como gurizada, abacaxizal e açaizeiro, por exemplo.

Com o auxílio da ferramenta de pesquisa do dicionário eletrônico Houaiss para formar o corpus, foi possível dividir as palavras com epêntese encontradas em dois grandes grupos: o das palavras cujas bases tinham a última sílaba tônica (como guaraná, café, abacaxi $\underline{i}$ e lundu, por exemplo) e o das palavras cujas bases tinham a última sílaba átona (como língua, milho, fogo). Formados os dois grupos, percebeu-se que, quando a tonicidade recaía na última sílaba, a consoante intrusiva preferida era

\footnotetext{
* Doutoranda na Universidade Federal do Rio Grande do Sul; mestre pela Pontifícia Universidade Católica do Rio Grande do Sul; samantasa@terra.com.br.

${ }^{1}$ Canfield (2010).
} 
/z/, formando guaranazal, cafezal, abacaxizeiro e lunduzeiro. Por outro lado, quando a última sílaba era átona, a preferência recaía sobre /r/, formando linguareiro, milharal, fogareiro.

A partir disso, foi possível estabelecer duas "regras default" para a epêntese consonantal. A primeira seria aplicada em palavras cujas bases têm a última sílaba tônica, considerando-se a vogal final como parte do radical, quando a consoante epentética é preferencialmente /z/, como guaraná > guaranazeiro. Já a segunda regra, que diz respeito a palavras cujas bases têm a última sílaba átona, ou seja, acabam em vogal temática, a consoante epentética apresentou maior variabilidade, mas se observou que o maior número de palavras recebeu /r/, como milho > milharal, ou uma outra consoante coronal, como /z/, /r/, /t/, /l/, /s/, /g/, por exemplo.

Bisol (2010) afirma que o uso de /z/ como epêntese remonta ao século XVIII. Isso, aliado ao fato de que os exemplos de palavras sufixadas cujas bases são oxítonas são numericamente superiores, sustenta, em alguma medida, a predição de que /z/ é a consoante epentética do português e que seria a preferida pelos falantes mesmo quando, pelo contexto (palavra sufixada cuja base não é oxítona), fosse esperada a entrada de $/ \mathrm{r} /$.

Para Morley (2017), assume-se que a epêntese consonantal é parte do repertório básico de gramáticas fonológicas. Segundo a autora, o fenômeno pode ser classificado como assimilativo, quando a identidade do segmento epentético é condicionada por ambiente fonético. Em contrapartida, chama-se epêntese consonantal default quando uma consoante não presente no input ou na forma subjacente aparece na forma de superfície, como seria o caso, em português, de abacaxi/abacaxizal, café/cafeteira, bicho/bicharada, por exemplo.

A epêntese consonantal default verificada no português brasileiro é o foco deste artigo. Nele, pretende-se, brevemente, retomar alguns estudos sobre epêntese consonantal em palavras derivadas por sufixo no português brasileiro; apresentar aspectos do status da consoante epentética, o que será seguido por sucintas considerações finais.

\section{Epêntese Consonantal no Português Brasileiro}

A epêntese, que pode ser consonantal ou vocálica, caracteriza-se pela inserção de segmento em palavras, cuja principal motivação é solucionar um problema estrutural, em geral de caráter silábico. A epêntese consonantal consiste no acréscimo de uma consoante na juntura morfemática de palavras derivadas, como cafezal $(c a f e ́+z+a l) \mathrm{e}$ milharal (milho $+r+a l$ ), por exemplo. Ao contrário da epêntese vocálica, em que a inserção da vogal se manifesta apenas na pronúncia, como em ad[e]vogado e p[i]neu, entre outras, a epêntese consonantal, no português brasileiro, é um fenômeno registrado na língua escrita.

Cagliari e Massini-Cagliari (2000) acreditam que a consoante intrusiva se caracteriza por adicionar a uma palavra um segmento sem justificação etimológica, com o efeito de facilitar uma pronúncia ou a percepção de sequências de segmentos sonoros, buscando adequação fonética ao contexto em que ocorrem. Para estudar a epêntese consonantal em português, usam a Teoria da Otimidade (TO).

Os autores reforçam que a epêntese consonantal em português ocorre somente na juntura morfemática interna das palavras derivadas e que tem como objetivo evitar o hiato, tradicionalmente preterido pela língua neste contexto $($ chá + eira $=$ chaleira $;$ café 
+ eira $=$ cafeteira ; tema + ico $=$ temático ). Ademais, frisam que um dos contextos mais comuns de epêntese acontece quando o radical termina por vogal, e o sufixo começa por vogal, tônica ou átona. Embora reiterem que o português tende a evitar hiatos, admitem sua formação, como em cajuína.

Massini-Cagliari (2000) e Cagliari (2000) mostram outras situações em que discutem a possibilidade da consoante introduzida ser epentética ou não, apresentando as opções de análise com breve discussão. Por outro lado, ao discutirem os sufixos de grau (diminutivo), assumem que o afixo pertence a duas categorias, uma com a consoante $\langle z>$ e outra sem ela. Na primeira, o sufixo funciona como palavra fonológica independente, produzindo palavras do tipo composição, e não derivação, o que não ocorre com os sufixos da segunda categoria. $O$ fato de as formas diminutivas apresentarem a inserção de uma consoante $\langle z\rangle$ mostra que o radical, seguido do diminutivo, acompanha a regra geral da derivação, uma vez que, na composição, não há consoantes epentéticas.

Cagliari (2001) afirma que, em muitas palavras do português brasileiro, a presença de consoante epentética adveio diretamente do latim, que aplicava a mesma regra de derivação (amplitude $=$ amplo $+i+t+u d e$ [do latim amplitudine]). Como os sufixos são elementos lexicais produtivos para a geração de novas palavras, o processo de epêntese passou para o português e continuou operante em palavras derivadas dentro da língua. Dessa forma, segundo o autor, mesmo em palavras sem origem latina (robótica $=$ robô $+t+i c a)$, a consoante primeiramente usada em latim era a escolhida em casos de epêntese.

Cagliari (2001) observa também que, em português, as consoantes epentéticas têm articulação coronal, como nos seguintes exemplos: lava-t-ório, temá-t-ico, lava-deira, move-d-iço, pau-l-ada, lingua-r-udo, cafe-z-al, trai-ç-ão, nomea-ç-ão. Em contrapartida, o autor detecta a presença de consoantes epentéticas não coronais, como em seus exemplo nari-g-udo, pagá-v-el e feri-m-ento, embora admita que o status dessas consoantes como epentéticas não seja muito claro, já que, no caso de narigudo, por exemplo, pode-se admitir a atuação da regra que transforma fricativas em oclusivas.

Canfield (2010) trata da epêntese consonantal do português brasileiro a partir de um corpus cujos dados foram captados através da ferramenta de pesquisa do dicionário eletrônico Houaiss. A pesquisa restringiu-se aos sufixos -ada, -al e -eiro, por terem sido considerados, dentre os afixos listados em algumas gramáticas, como as de Ribeiro (1950), de Said Ali (1964), de Almeida (1967), de Bechara (1999) e de Rocha Lima (2002), como os mais produtivos em temos de inserção de consoante.

As palavras nas quais foi identificada a ocorrência da epêntese consonantal foram separadas em três grupos, um para cada um dos sufixos previamente escolhidos. Esses grupos foram subdivididos respeitando a tonicidade da última sílaba da palavrabase, criando dois subgrupos para cada sufixo, conforme pode ser visto nos itens (1), (2) e (3), desenvolvidos abaixo.

\section{(1) Palavras derivadas com o sufixo -ada}

As palavras formadas com esse sufixo que apresentam epêntese perfazem um total de 36, sendo 23 derivadas de bases que possuem a sílaba final tônica. Dessas, as 21 que constituem o grupo 1a (base atemática), apresentam /z/ como consoante epentética. As duas palavras restantes, chapelada e paulada, que foram, em um primeiro momento, incluídas no corpus, ao invés de /z/, como esperado, têm /1/. Cabe frisar que, dentre as 
ocorrências, não há nenhuma variação com hiato.

\section{Grupo 1a}
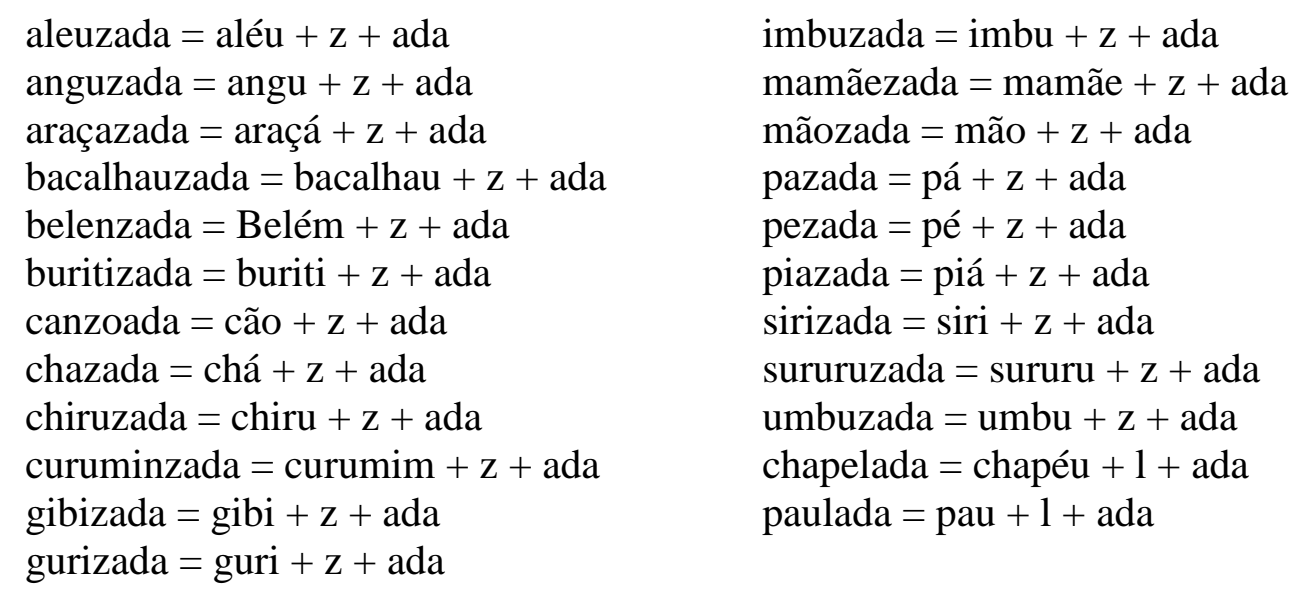

O grupo 1b, a seguir, composto por palavras-base que mantêm a vogal temática, tem 13 itens. Todos apresentam /r/ como consoante intrusiva (o que torna esse o mais homogêneo dos grupos da pesquisa).

\section{Grupo 1b}

$\begin{array}{ll}\text { bicharada }=\text { bicho }+r+\text { ada } & \text { fumarada }=\text { fumo }+r+\text { ada } \\ \text { chinarada }=\text { china }+r+\text { ada } & \text { galharada }=\text { galho }+r+\text { ada } \\ \text { chuvarada }=\text { chuva }+r+\text { ada } & \text { gentarada }=\text { gente }+r+\text { ada } \\ \text { cusparada }=\text { cuspe }+r+\text { ada } & \text { laçarada }=\text { laço }+r+\text { ada } \\ \text { espumarada }=\text { espuma }+r+\text { ada } & \text { linguarada }=\text { língua }+r+\text { ada } \\ \text { filharada }=\text { filho }+r+\text { ada } & \text { milharada }=\text { milho }+r+\text { ada }\end{array}$

folharada $=$ folha $+r+$ ada

\section{(2) Palavras derivadas com o sufixo -al}

O grupo 2a conta com 53 palavras derivadas, cujas bases apresentam a vogal final acentuada. Neste grupo, todas as palavras derivadas apresentam /z/ como consoante epentética. Ainda assim, entre essas, há a presença de caroatal, variante de caroazal, que segue a regra.

Além disso, é nesse grupo que se observam registradas no dicionário mais variações com hiato (babaçu>babaçuzal babaçual, bambu>bambuzal bambual, caju> cajuzal cajual). Há também formas variantes em que não ocorre a epêntese (capim> capinzal capinal e caraguatá > caraguatazal caraguatal).

\section{Grupo 2a}

$$
\begin{array}{ll}
\text { abacaxizal }=\text { abacaxi }+\mathrm{z}+\mathrm{al} & \text { guaranazal }=\text { guaraná }+\mathrm{z}+\mathrm{al} \\
\text { açaizal }=\text { açaí }+\mathrm{z}+\mathrm{al} & \text { igapozal }=\text { igapó }+\mathrm{z}+\mathrm{al} \\
\text { acurizal }=\text { acuri }+\mathrm{z}+\mathrm{al} & \text { imburizal }=\text { imburi }+\mathrm{z}+\mathrm{al} \\
\text { aguapezal }=\text { aguapé }+\mathrm{z}+\mathrm{al} & \text { imbuzal }=\text { imbu }+\mathrm{z}+\mathrm{al}
\end{array}
$$




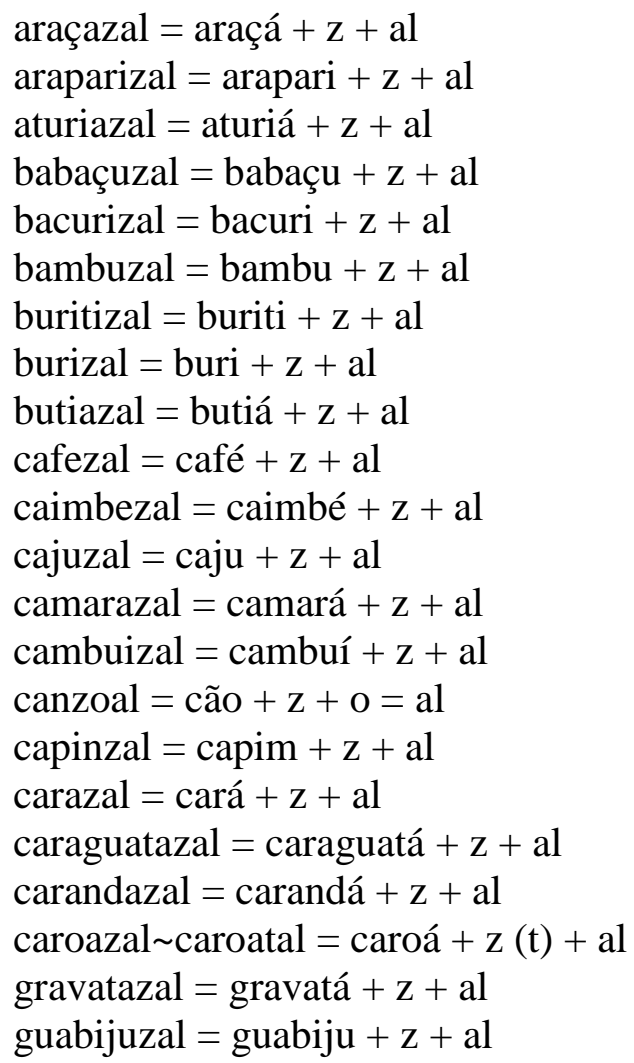

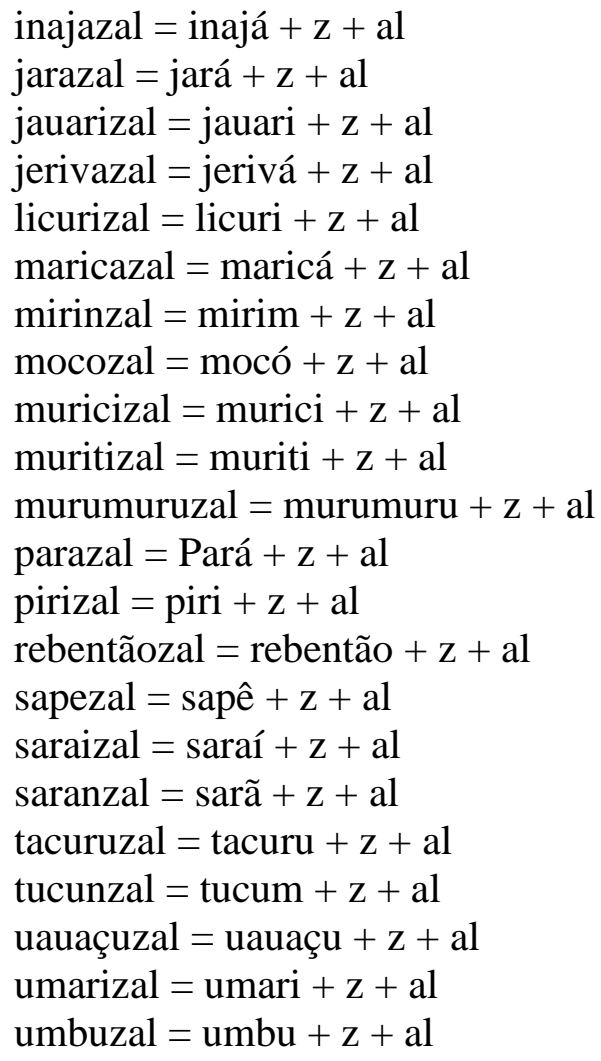

O grupo $2 \mathrm{~b}$ é composto por sete palavras que têm as bases terminadas em vogal temática. É o grupo que possui maior diversidade em relação à consoante intrusiva, uma vez que foi observada a entrada de /s/, /g, /r/, /z/.

\section{Grupo 2b}

$$
\begin{array}{ll}
\text { ervaçal }=\text { erva }+c ̧+a l & \text { linguaral }=\text { língua }+r+a l \\
\text { lamaçal }=\text { lama }+c ̧+a l & \text { milharal }=\text { milho }+r+a l \\
\text { lodaçal }=\text { lodo }+c ̧+a l & \text { manguezal }=\text { mangue }+\mathrm{z}+\mathrm{al}
\end{array}
$$

\section{(3) Palavras derivadas com o sufixo -eiro}

O grupo 3a, com bases atemáticas, é o mais numeroso: conta com 86 palavras, das quais 82 apresentam /z/ como consoante epentética. As demais quatro apresentam $/ \mathrm{t} / \mathrm{s}$

\section{Grupo 3a}

abacaxizeiro $=$ abacaxi $+\mathrm{z}+$ eiro abricozeiro $=$ abricó $+\mathrm{z}+$ eiro acaçuzeiro $=$ acaçu $+z+$ eiro açaizeiro $=$ açaí $+\mathrm{z}+$ eiro aguaizeiro $=$ aguaí $+z+$ eiro alecrinzeiro $=$ alecrim $+z+$ eiro amapazeiro $=$ amapá $+\mathrm{z}+$ eiro

$$
\begin{aligned}
& \text { ingazeiro }=\text { ingá }+\mathrm{z}+\text { eiro } \\
& \text { jacarezeiro }=\text { jacaré }+\mathrm{z}+\text { eiró } \\
& \text { jembezeiro }=\text { jembê }+\mathrm{z}+\text { eiro } \\
& \text { jeribazeiro }=\text { jeribá }+\mathrm{z}+\text { eiro } \\
& \text { jerimunzeiro }=\text { jerimum }+\mathrm{z}+\text { eiro } \\
& \text { jerivazeiro }=\text { jerivá }+\mathrm{z}+\text { eiro } \\
& \text { juazeiro }=\text { juá }+\mathrm{z}+\text { eiro }
\end{aligned}
$$




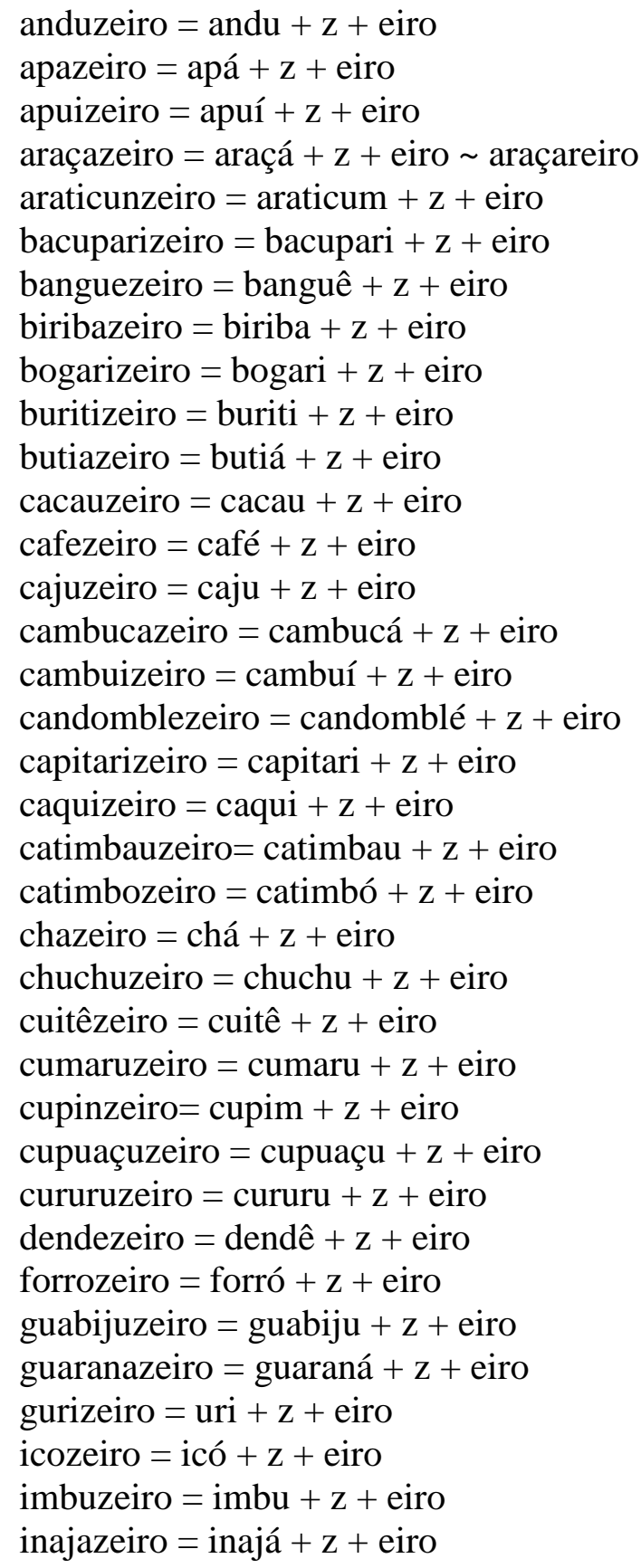

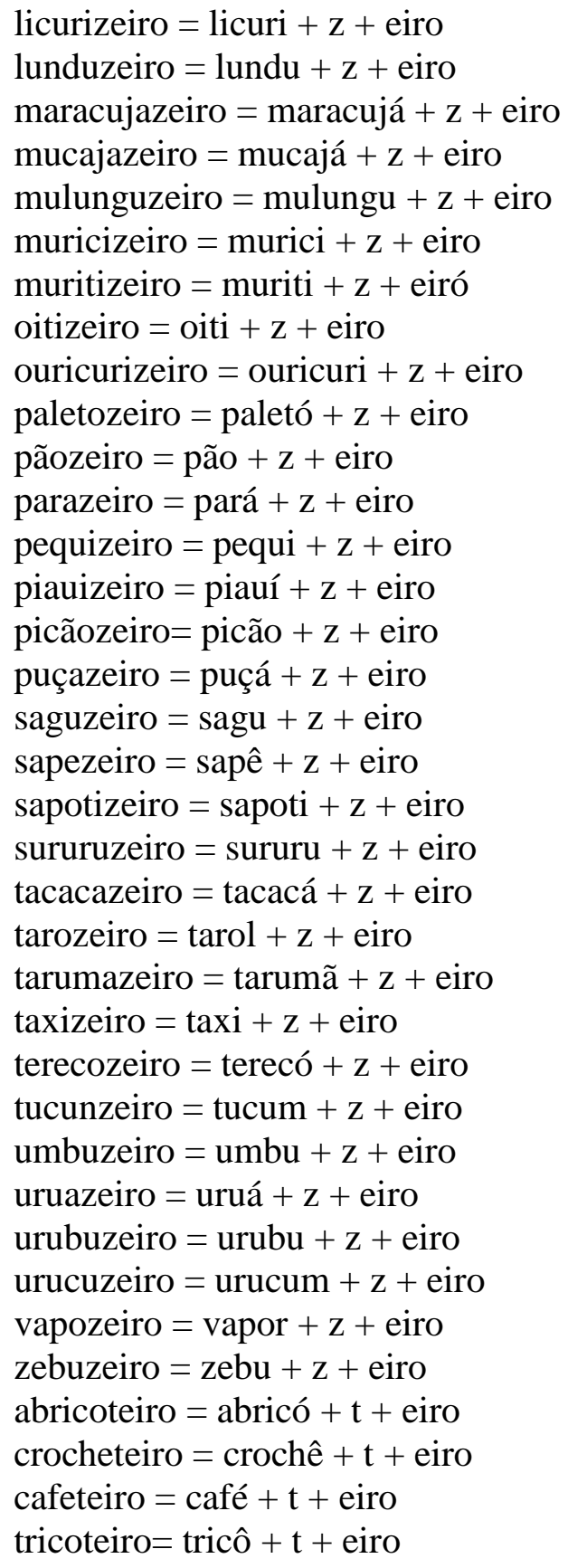

licurizeiro $=$ licuri $+z+$ eiro

lunduzeiro $=$ lundu $+z+$ eiro

maracujazeiro $=$ maracujá $+\mathrm{z}+$ eiro

mucajazeiro $=$ mucajá $+z+$ eiro

mulunguzeiro $=$ mulungu $+\mathrm{z}+$ eiro

muricizeiro $=$ murici $+\mathrm{z}+$ eiro

muritizeiro $=$ muriti $+\mathrm{z}+$ eiró

ouricurizeiro $=$ ouricuri $+\mathrm{z}+$ eiro

paletozeiro $=$ paletó $+\mathrm{z}+$ eiro

pãozeiro $=$ pão $+z+$ eiro

parazeiro $=$ pará $+z+$ eiro

pequizeiro $=$ pequi $+\mathrm{z}+$ eiro

piauizeiro $=$ piaui $+z+$ eiro

puçazeiro = puça $+z+$ iro

saguzeiro $=$ sagu $+\mathrm{z}+$ eiro

sapezeiro $=$ sapê $+z+$ eiro

sapotizeiro $=$ sapoti $+z+$ eiro

sururuzeiro $=$ sururu $+\mathrm{z}+$ eiro

tacacazeiro $=$ tacacá $+\mathrm{z}+$ eiro

tarozeiro $=$ tarol $+\mathrm{z}+$ eiro

tarumazeiro $=$ tarumã $+\mathrm{z}+$ eiro

taxizeiro $=\operatorname{taxi}+\mathrm{z}+$ eiro

terecozeiro $=$ terecó $+\mathrm{z}+$ eiro

eiro

unbuzeiro $=$ umbu $+z+$ eiro

uruazeiro $=$ uruá $+z+$ eiro

urubuzeiro $=$ urubu $+\mathrm{z}+$ eiro

urucuzeiro $=$ urucum $+\mathrm{z}+$ eiro

vapozeiro $=$ vapor $+\mathrm{z}+$ eiro

zebuzeiro $=$ zebu $+\mathrm{z}+$ eiro

abricoteiro $=$ abricó $+\mathrm{t}+$ eiro

crocheteiro $=$ crochê $+\mathrm{t}+$ eiro

tricoteiro $=$ tricô $+\mathrm{t}+$ eiro

O grupo 3 b é composto por apenas três palavras derivadas cujas bases são terminadas em vogal temática.

\section{Grupo 3b}

fogareiro $=$ fogo $+\mathrm{r}+$ eiro

linguareiro $=$ língua $+r+$ eiro

ervateiro $=$ erva $+\mathrm{t}+$ eiro

Analisando cada um desses subgrupos, foi possível depreender que /z/ é a consoante epentética default no português brasileiro para as palavras-base atemáticas e 
que /r/ é default para as palavras-base terminadas em vogal temática.

Nos quadros abaixo, são resumidos os resultados encontrados a partir do corpus apresentado acima: o Quadro 1 apresenta as palavras cuja tonicidade da palavra primitiva recai na última sílaba (palavras atemáticas), e o Quadro 2, as palavras cuja palavra primitiva tem como sílaba tônica a penúltima (palavras atemáticas):

Quadro 1 - Resultados, encontrados no corpus, de epêntese em palavras derivadas cujas primitivas são oxítonas

\begin{tabular}{|c|c|c|c|}
\hline Sufixo & $\begin{array}{l}\text { Total de } \\
\text { palavras } \\
\text { com os } \\
\text { sufixos } \\
\text { escolhidos } \\
\text { no corpus }\end{array}$ & $\begin{array}{c}\text { Número de } \\
\text { palavras com } \\
\text { entrada de /z/ } \\
\text { no corpus }\end{array}$ & $\begin{array}{l}\text { Número de palavras com outras } \\
\text { consoantes no corpus }\end{array}$ \\
\hline -ada & 23 & 21 & $\begin{array}{c}\mathbf{2} \\
\text { (chapelada e paulada) }\end{array}$ \\
\hline -al & 53 & 53 & $\begin{array}{c}\text { 0, mas } 6 \text { têm variação } \\
(\text { babaçu > babaçuzal babaçual, } \\
\text { bambu > bambuzal bambual, } \\
\text { caju > cajuzal cajual, } \\
\text { capim > capinzal } \sim \text { capinal e } \\
\text { caraguatá > caraguatazal caraguatal })\end{array}$ \\
\hline \multirow[t]{2}{*}{-eiro } & 86 & 82 & $\begin{array}{c}\mathbf{4} \\
\text { (sempre t: abricoteiro, crocheteiro, } \\
\text { tricoteiro e cafeteiro) } \\
\text { e 8 com variação } \\
\text { (alecrim }>\text { alecrinzeiro alecrineiro, } \\
\text { cupim }>\text { cupinzeiro } \sim \text { cupineiro, } \\
\text { urucum }>\text { urucunzeiro } \sim \text { urucueiro, } \\
\text { cacau }>\text { cacauzeiro cacaueiro } \\
\sim \text { cacoeiro, } \\
\text { caju }>\text { cajuzeiro cajueiro, } \\
\text { guabiju }>\text { guabijuzeiro guabijueiro, } \\
\text { zebu }>\text { zebuzeiro } \sim \text { zebueiro, } \\
\text { araçazeiro araçareiro) }\end{array}$ \\
\hline & 164 & 136 & \\
\hline
\end{tabular}

Em palavras derivadas cujas bases são oxítonas, os três sufixos (-ada, -al e -eiro) apresentam, majoritariamente, a entrada de /z/ como consoante epentética. Algumas das palavras que apresentam outra consoante, como abricoteiro, crocheteiro, tricoteiro, não foram consideradas casos de epêntese consonantal por serem derivadas de palavras terminadas por consoante em sua origem (abricot, crochet e tricot).

No caso de chapelada, o processo de sufixação retoma sua forma antiga com [1] do francês antigo (chapel); não se enquadra, portanto, em caso epêntese, assim como as formas abricoteiro, crocheteiro, tricoteiro. A forma chapéu do português apresenta-se $\mathrm{com} / \mathrm{u} /$ porque a vocalização da lateral permaneceu na escrita. Walsh (1995) afirma que todas as laterais podem ser classificadas como segmentos complexos corono- 
dorsais e, quando laterais, perdem o traço coronal. Nesse caso, o segmento dorsal resultante é quase sempre um vocoide. No português brasileiro, os dois traços distribuem-se da seguinte maneira: a lateral se manifesta [-post] antes de vogal, em sílabas CV ou CCV (lata, placa) e [+post] na coda de sílaba (final $>$ finaw) na maioria dos dialetos.

Em paulada, a lateral não substitui o glide, mas aparece a seu lado. A escolha pela lateral como consoante introduzida na sufixação é encontrada em outras palavras derivadas de pau registradas no dicionário eletrônico Houaiss, como paulama e paulito.

No caso de cafeteiro, parece que a consoante é de fato epentética e distinta da regra default, ainda que se possa pensar que essa palavra, embora com significado diferente, seja utilizada por analogia à cafeteira, "máquina ou aparelho em que se faz café ('bebida') automática ou semiautomaticamente".

Quadro 2 - Resultados, encontrados no corpus, de epêntese em palavras derivadas cujas primitivas são paroxítonas

\begin{tabular}{|c|c|c|c|}
\hline Sufixo & $\begin{array}{c}\text { Total de palavras } \\
\text { com os sufixos } \\
\text { escolhidos no } \\
\text { corpus }\end{array}$ & $\begin{array}{c}\text { Número de } \\
\text { palavras com } \\
\text { entrada de } / \mathbf{r} / \text { no } \\
\text { corpus }\end{array}$ & $\begin{array}{c}\text { Número de palavras com } \\
\text { outras consoantes no } \\
\text { corpus }\end{array}$ \\
\hline -ada & 13 & 13 & $\mathbf{0}$ \\
\hline -al & 7 & 2 & $\begin{array}{c}\mathbf{5} \\
\text { (ervaçal, lamaçal, lodaçal, } \\
\text { matagal e manguezal) }\end{array}$ \\
\hline -eiro & 3 & 2 & $\begin{array}{c}\mathbf{1} \\
\text { (ervateiro) }\end{array}$ \\
\hline Total & 23 & 17 & 6 \\
\hline
\end{tabular}

Em palavras derivadas cujas bases são paroxítonas, a relação de palavras é menos expressiva. A entrada da consoante esperada (ou seja, /r/), ocorre apenas quando se trata do sufixo -ada, o qual não apresenta outra consoante. Com o sufixo -al, tem-se o grupo que, além de ser o que menos aparece $/ \mathrm{r} /$, apresenta a maior variabilidade de consoantes, pois, nele, estão as palavras ervaçal, lamaçal, lodaçal, matagal, manguezal. Apenas linguaral e milharal "obedeceriam" à regra. Com o sufixo -eiro, apenas ervateiro, das três palavras do grupo, não apresenta /r/.

Em uma perspectiva semelhante à de Canfield (2010) quanto ao exame de dados em dicionário, Pires (2016) empreende uma análise morfofonológica e etimológica de palavras com a terminação -ada retiradas de Houaiss (2009), com o objetivo de analisar palavras de base nominal que apresentam epêntese consonantal. Nesse estudo, os dados foram separados em três grupos, compostos por palavras derivadas de base nominal; palavras derivadas de base verbal; palavras com a terminação -ada não sufixal. A autora constatou que palavras derivadas de bases temáticas e atemáticas, com relação à inserção de consoante, têm comportamento distinto no português brasileiro, qual seja: palavras de bases cuja vogal final não é temática, na derivação, de modo geral, inserem /z/, consonante menos invasiva, que apenas resolve o problema de caráter silábico (pá + -ada > pazada); palavras de bases temáticas inserem /r/ e neutralizam a vogal temática da base, substituindo-a por /a/ (bicho + -ada > bicharada).

Para Pires (op. cit.), no português brasileiro, o contexto mais favorável para as 
inserções consonantais é o grupo das palavras de base atemática ${ }^{2}$. Dentro desse grupo, o contexto mais favorável é o das palavras terminadas em vogal candidata a acento.

A autora oferece motivos para que, no português brasileiro, haja a seleção de consoantes além de /z/ e /r/. Entre as razões, estão semelhança com outras palavras da língua, variação (cf. bambu < bambucada bambuzal bambuØal) e casos de vestígio etimológico (cf. paulada). Por fim, lança a hipótese de /r/ estar cristalizado na língua e $\mathrm{de} / \mathrm{z} /$ ser a consoante de inserção regular vigente na língua.

\section{Status da consoante epentética}

Como afirmado anteriormente, em alguns casos, o processo de derivação sufixal envolve uma consoante epentética entre a palavra primitiva e o sufixo. A seguir, foi feita uma breve exposição do tratamento dado a essa consoante por alguns autores, entre gramáticos e linguistas.

Segundo Cagliari (1999, p. 17), essa consoante, "cuja função fonológica é não permitir que ocorra hiato (ou ditongo) entre a vogal final da raiz e a vogal inicial do sufixo", é chamada de intrusiva e é, comumente, $[\mathrm{t}]$ ou $[\mathrm{z}]$. O autor cita como exemplos palavras como aquático, juventude, cafezinho, pobrezinho.

Essa consoante é chamada de consoante de ligação por alguns gramáticos, como Luft (2002), Cunha (1970) e Cegalla (1991), e serve para facilitar a pronúncia quando acontece a união de duas vogais, uma do final da palavra e outra do início do sufixo. Cunha (1970, p. 47) afirma que há elementos mórficos que entram no vocábulo agregando a ele valor significativo ou gramatical: "Há, porém, outros que não são significativos, e servem apenas para evitar dissonâncias (hiatos, encontros consonantais) na juntura daqueles elementos.” Luft (2002, p. 94) apresenta as consoantes [1], [t] e [z] de palavras como chaleira, cafeteira e capinzal como sendo de ligação e refuta a ideia de esses segmentos puramente eufônicos serem infixos, e cita Mattoso Camara (1964, p. 147):

\footnotetext{
Não é uma boa técnica gramatical classificar como infixos os fonemas parasitos que figuram em certos derivados portugueses, como capinzal (capim + al), por dois motivos: 1) a intercalação não é no radical; 2) o fonema parasito não tem valor gramatical próprio e só dá uma variante de sufixo (-zal::-al). (LUFT, 2002, p.94)
}

Na relação de sufixos nominais e verbais nas gramáticas do português, em geral, os afixos são considerados iniciados por vogal. Quando alguma consoante se faz presente, não há menção se ela é epentética ou se há motivação para que isso ocorra.

Outros sufixos aparecem como iniciados com consoantes, como, por exemplo, dade (maldade, crueldade); -ficar (falsificar, petrificar); -lândia (cafelândia); -tude (amplitude, magnitude). A maioria dos sufixos, de qualquer forma, apresenta-se iniciada por vogal.

Algumas dessas consoantes adviriam do latim. No caso do sufixo -or (fulgor, condutor, armador, ascensor), Said Ali (1964, p. 112) afirma que as consoantes "D, T e S pertencem a temas do particípio do pretérito".

\footnotetext{
${ }^{2}$ Para Mattoso Camara (1981), atemáticas são as palavras em vogal tônica, como sofá, café, tupi, jiló e tatu, por exemplo
} 
Não é claro na literatura a que "base" pertence a consoante criada em algumas palavras na derivação sufixal. Alguns autores defendem que ela faz parte do sufixo; outros, que ela é um elemento intrusivo de função estrutural.

No caso do sufixo -inho, segundo Bisol,

o sufixo diminutivo é tão somente -inho, que se manifesta com -z epentético
para satisfazer exigências estruturais, ou seja, para atender a certos princípios
ativos na interação da morfologia com a fonologia que são fundamentais para
organização deste derivativo. (BISOL, 2010, p.63)

Um desses princípios, segundo a Teoria da Otimidade, é a restrição que exige que toda a sílaba tenha um onset, que, conforme Bisol (2010), está mais alta na hierarquia que DEP-IO, restrição que proíbe a epêntese por exigir que todo o segmento do output tenha correspondente no input.

$\mathrm{Na}$ conclusão do artigo, Bisol (2010) reforça que a definição de -Z como epêntese remonta ao século XVIII e que se estende a outros derivativos, como al zal, eiro zeiro, por exemplo.

Em contrapartida, Schwindt (2013, p. 24) afirma que "o português é pródigo em exemplos de vocábulos em que, em nível de superfície, não se detecta qualquer segmento interveniente entre raiz e sufixo", independentemente de o sufixo iniciar por vogal ou consoante. Essa evidência, segundo Schwindt, põe em xeque a hipótese de evitação do hiato e a necessidade de alinhamento do sufixo a um onset, uma vez que há muitas palavras que apresentam hiato ou sílaba sem onset (como heroína e canoeiro, por exemplo).

Guimarães e Nevins (2013) refutam a ideia de Mattoso Camara $(1953,1970)$ de que palavras terminadas em vogal nasal tenham uma consoante nasal subjacente como [n] epentético/de ligação em pares nos quais não há evidência de uma nasal subjacente na base, como Tupi/Tupinista e faraó/faraônico.

Em um primeiro momento, esses pares não podem ser tomados automaticamente como contraevidência à ideia de um /n/ subjacente no fim das bases. De fato, tais pares podem ser tomados como evidência de bases como tupin e faraon, uma vez que as especificações de traços da consoante /n/ que emerge em palavras complexas (como tupinista, faraônico) não é predizível a partir do sufixo sozinho ou a partir de qualquer regra morfofonológica de epêntese (que tende a dar origem a [z] no português brasileiro). Isso parece estar em consonância com a amplamente aceita análise de Bisol (1992), na qual todas as palavras oxítonas terminadas em sílaba aberta na superfície teriam uma consoante subjacente no fim, dando origem à sílaba pesada que atrai o acento.

Guimarães e Nevins (2013) afirmam que, em ampla maioria dos casos, a consoante que emerge entre a raiz e os muitos sufixos possíveis é [z] - claramente a consoante epentética default na língua - mesmo quando a raiz termina com uma consoante (odor > odorzão/*odorão). Este é um padrão produtivo da língua, atestado com muitos sufixos (-ão, -inho, -ólogo, -ologia, -eiro, -aço, -ice, -ista, -ada, etc), aplicados em um amplo número de palavras cuja contraparte termina com uma vogal nasal. De cupim, por exemplo, encontra-se cupinzeiro; de marrom, encontra-se amarronzado, não amarronado; de maçã, encontra-se maçãzada, não maçãnada.

O padrão pode ser atestado de forma ainda mais clara quando se observam palavras trazidas para ilustrar o ponto de vista de Mattoso Camara. Por exemplo, de bom, fã e som, encontram-se bonzão, fanzaço e sonzeira, respectivamente. O mesmo é 
verdade para palavras como Tupi, faraó, as quais não exibem uma vogal nasal na base, mas apresentam [n] na superfície em algumas palavras aparentemente derivadas (tupinista, faraônico). Quando tais bases combinam com a maioria dos sufixos, sistematicamente, observamos [z] epentético entre base e sufixos. Por exemplo, de faraó, temos faraozaço, faraozice e enfaraozado.

\section{Considerações Finais}

A epêntese consonantal no português brasileiro, bastante observada em palavras derivadas por sufixo, ainda é um fenômeno pouco estudado. Entretanto, a maioria dos autores aponta que ela é um mecanismo utilizado pela língua para evitar o hiato e, portanto, estaria diretamente ligada ao processo de silabificação. De qualquer maneira, esta possibilidade de a evitação do hiato ser uma exigência da língua já está sendo discutida por alguns autores, uma vez que palavras que preservam o hiato na derivação sufixal, como cajuína, não são vistas como problemáticas.

Partindo da análise de alguns textos, é possível depreender que /z/ tem sido considerada a consoante epentética default da língua. De qualquer maneira, parece importante frisar que se pode constatar que o traço coronal se destaca quando outra consoante aparece na juntura morfemática das palavras derivadas (como no caso de filharada, lamaçal e caroatal,).

Desde a composição do corpus de Canfield (2010), alguns fatos interessantes foram observados. Em primeiro lugar, as palavras derivadas com o acréscimo dos sufixos -ada, -al e -eiro puderam ser divididas em dois grandes grupos: palavras cujas bases têm a última sílaba tônica, ou seja, a vogal final é parte do radical; e palavras cujas bases têm a última sílaba átona, ou seja, acabam em vogal temática.

Quando a tonicidade recaía na última sílaba, a consoante intrusiva preferida era /z/. Por outro lado, quando a última sílaba se apresentava átona, a escolha por $/ \mathrm{r} / \mathrm{era}$ preferida, permitindo estabelecer duas regras default para a epêntese consonantal. A primeira para as palavras-base que acabam em vogal do radical e a segunda para as palavras-base acabadas em vogal temática.

Palavras que, aparentemente, apresentavam consoante epentética, como chapelada e abricoteiro, não tiveram a análise confirmada, e a explicação para a preferência por essas consoantes foi particularizada. Os raros casos de exceção recebem um diacrítico no léxico e são silabificadas antes da regra default.

Ainda que essa análise merecesse um estudo mais amplo, sobretudo quanto à inclusão de outros afixos, acredita-se que o que foi feito delineia um quadro bastante coerente da epêntese consonantal no português brasileiro, sedimentado na teoria fonológica.

\section{REFERÊNCIAS}

ALI, M. Said. Gramática secundária da língua portuguêsa. São Paulo: Melhoramentos, 1964.

BISOL, Leda. A sílaba e seus constituintes. In: NEVES, Maria Helena de Moura. Gramática do português Falado: Volume VII: Novos estudos. Campinas: Unicamp, 1999, p. 701-742. 
BISOL, Leda. O diminutivo e suas demandas D.E.L.T.A., 26:1, 2010 (59-85)

CAGLIARI, Luiz Carlos. A regra de atribuição de acento via afixos. Português no Brasil: Estudos Fonéticos e Fonológicos. Aguilera, Vanderci de Andrade (org.). Londrina: Editora UEL, 1999, p. 11-35.

CAGLIARI, Luiz Carlos. Consoantes epentéticas em Português. In: $6^{\circ}$ Congresso Internacional da Associação de Lusitanistas (AIL). Anais do $6^{\circ}$ Congresso Internacional da Associação de Lusitanistas. Rio de Janeiro: Associação Internacional de Lusitanistas, 2001.

CAGLIARI, Luiz Carlos; MASSINI-CAGLIARI, G. A epêntese consonantal em português e sua interpretação na teoria da otimalidade. Revista de Estudos da Linguagem. Minas Gerais: USMG, 2000, p. 163-192.

CAMARA, Joaquim Mattoso Jr. Dicionário de Lingüistica e Gramática: Referente à Língua Portuguesa. 9.ed. Petrópolis: Vozes, 1981.

CANFIELD, Samanta Sá. A epêntese consonantal no português : um estudo introdutório. 2010. 57 f. Dissertação (Mestrado em Letras) - Pontifícia Universidade Católica do Rio Grande do Sul, Porto Alegre, 2010.

CEGALLA, Domingos Paschoal. Novíssima Gramática da Língua Portuguesa. 34.ed. São Paulo: Companhia Editorial Nacional, 1991.

CUNHA, Celso. Gramática Moderna. Belo Horizonte, 2.ed.Editora Bernardo Álvares, 1970.

GUIMARÃES, Maximiliano; NEVINS, Andrew. Probing the Representation of NASAL Vowels in Brazilian portuguese with language games. Revista Organon, Porto Alegre, v. 28, n. 54, p. 155-178, jan./jun. 2013.

LUFT, Celso Pedro. Moderna gramática brasileira. 15.ed. São Paulo, Globo, 2002. MORLEY, Rebecca. Is Phonological Consonant Epenthesis Possible? A Series of Artificial Grammar Learning Experiments, 2017. No prelo.

PIRES, Caroline de Castro. Epêntese Consonantal em Contexto de Juntura Morfêmica: Considerações sobre o sufixo -ada. Dissertação de mestrado. PUCRS, 2016.

SCHWINDT, Luiz Carlos. Palavra fonológica e derivação em português brasileiro: considerações para a arquitetura da gramática. Leda Bisol; Gisela Collischonn (Org.). In: Fonologia: teorias e perspectivas. 1 ed. Porto Alegre: EDIPUCRS, p. 15-28, 2013. 